Article

\title{
Loads of Coliforms and Fecal Coliforms and Characterization of Thermotolerant Escherichia coli in Fresh Raw Milk Cheese
}

\author{
Ahmed M. Hammad ${ }^{1}$, Amira Eltahan ${ }^{1}$, Hamdy A. Hassan ${ }^{2,3}{ }^{\mathbb{D}}$, Nasser H. Abbas ${ }^{2}$ (D) Heba Hussien ${ }^{1}$ \\ and Tadashi Shimamoto ${ }^{4, *(1)}$
}

1 Department of Food Hygiene and Control, Faculty of Veterinary Medicine, University of Sadat City, Sadat City 32897, Egypt; hammad@vet.usc.edu.eg (A.M.H.); amira.eltah@gmail.com (A.E.); hebashelaby2013@yahoo.com (H.H.)

2 Department of Environmental Biotechnology, Genetic Engineering and Biotechnology Research Institute, University of Sadat City, Sadat City 32897, Egypt; hamdy.hassan@gebri.usc.edu.eg (H.A.H.); nasser.abbas@gebri.usc.edu.eg (N.H.A.)

3 Department of Biological Science, Faculty of Science and Humanity Studies at Al-Quwayiyah, Riyadh 11961, Saudi Arabia

4 Laboratory of Food Microbiology and Hygiene, Graduate School of Integrated Sciences for Life, Hiroshima University, Higashi-Hiroshima 739-8528, Japan

* Correspondence: tadashis@hiroshima-u.ac.jp

check for updates

Citation: Hammad, A.M.; Eltahan,

A.; Hassan, H.A.; Abbas, N.H.;

Hussien, H.; Shimamoto, T. Loads of Coliforms and Fecal Coliforms and Characterization of Thermotolerant Escherichia coli in Fresh Raw Milk Cheese. Foods 2022, 11, 332. https:// doi.org/10.3390/foods11030332

Academic Editors: Juan Antonio

Centeno and Javier Carballo

Received: 22 December 2021

Accepted: 20 January 2022

Published: 25 January 2022

Publisher's Note: MDPI stays neutral with regard to jurisdictional claims in published maps and institutional affiliations.

Copyright: (C) 2022 by the authors. Licensee MDPI, Basel, Switzerland. This article is an open access article distributed under the terms and conditions of the Creative Commons Attribution (CC BY) license (https:/ / creativecommons.org/licenses/by/ $4.0 /)$.

\begin{abstract}
The aim of this study was to assess the hygienic status of raw milk cheese and determine the trends of virulence and antimicrobial resistance in thermotolerant Escherichia coli. Two hundred samples of karish, a popular Egyptian fresh raw milk cheese, were analyzed for coliforms and fecal coliforms using a standard most probable number (MPN) technique. Overall, $85 \%$ of samples were unsuitable for consumption, as they exceeded Egyptian standards for coliforms (10 MPN/g), and 65\% of samples exhibited coliforms at $44.5^{\circ} \mathrm{C}$. Of 150 recovered thermotolerant strains, $140(93.3 \%)$ were identified as E. coli. Importantly, one Shiga toxin-producing E. coli (STEC) strain carrying a striking virulence pattern, st $x 1-$, st $x 2+$, eae-, was detected. Eleven strains $(7.8 \%, 11 / 140)$ showed resistance to third-generation cephalosporins. Antibiotic resistance genes included $b l a_{\mathrm{SHV}}, b l a_{\mathrm{CTX}-\mathrm{M}}, q n r S$, tet (A), and tet(B), which were present in $4.3 \%, 2.8 \%, 0.71 \%, 2.1 \%$, and $0.71 \%$ of isolates, respectively. In conclusion, this study indicated that hygienic-sanitary failures occurred throughout the production process of most retail karish cheese. Furthermore, our findings emphasize the need for adopting third-generation cephalosporin-resistant $E$. coli as an indicator for monitoring antimicrobial resistance in raw milk cheese to identify the potential public health burden associated with its consumption.
\end{abstract}

Keywords: thermotolerant coliforms; cheese; antibiotic resistance; virulence; Shiga toxin-producing E. coli (STEC)

\section{Introduction}

Cheese making is a primary industry worldwide. In general, cheese is still made on a relatively small scale. The traditional practices for preparing raw milk cheeses account for the rich diversity of cheeses available [1]. Several types of fresh raw milk cheeses are consumed worldwide, such as quark, chevre, ricotta, cottage, and queso fresco. Karish is the most popular fresh cheese in Egypt. Like quark and cottage cheese, karish cheese is manufactured without the addition of rennet. It is an ancient type of white, soft, lactic cheese made from curdled skim milk curd, "Laban Rayeb", and neither acidifying agents nor lactic acid bacteria are added. However, lactic acid is created when lactose is fermented by the endogenous microflora of milk during the cheesemaking process, which is potent against some bacteria [2]. In general, bacterial contamination of raw milk during the milking process or from environmental sources (such as contaminated water or milking equipment) is a significant contributor to the microbial contamination of raw milk cheeses [3,4]. In 
processing plants, workers' hands and cheese-contact surfaces have been recognized as primary sources for contamination with spoilage and pathogenic bacteria [2].

Coliforms are a group of Gram-negative, non-spore-forming, rod-shaped aerobes and facultative anaerobes that inhabit the intestinal tract of all vertebrates. They can ferment lactose when incubated at $35-37^{\circ} \mathrm{C}$, producing acid and gas [5]. The coliform bacteria that grow at $44.5^{\circ} \mathrm{C}$ are referred to as fecal coliforms, including Escherichia coli, Klebsiella pneumoniae, Enterobacter agglomerans, Enterobacter aerogenes, Enterobacter cloacae, and Citrobacter freundii [6]. It is now clear that the ability of fecal coliforms to grow at high temperatures has little relationship with their fecal origin [7]. However, fecal coliforms are considered more directly associated with fecal contamination of mammals than other members of the coliform group [8]. Therefore, in the European Union, New Zealand, and Australia, the "fecal coliform" term has been substituted by what is considered a more suitable descriptor of this group of bacteria, "thermotolerant coliforms" (THC) [9]. Of note, despite misinterpretation of results of the coliform assay, current food and water quality regulations all over the world are still primarily based on coliform concentrations. They are a commonly used indicator of the hygienic quality of foods and water. It should be mentioned that the Egyptian standard of karish cheese lacks a limit for fecal coliform counts, and thus the acceptability of karish cheese is based on the count of coliforms [10].

E. coli is an extremely diverse species, including strains with little or no pathogenic potential and those that have acquired chromosomal or extra-chromosomal virulence operons to become highly infectious and virulent towards humans, animals, or both [11]. Pathotypes of diarrheagenic $E$. coli are grouped according to their virulence genes into enteropathogenic E. coli (EPEC), enterotoxigenic E. coli (ETEC), enteroinvasive E. coli (EIEC), diffuse adherent $E$. coli (DAEC), enteroaggregative E. coli (EAEC), adherent-invasive E. coli (AIEC), cell-detaching E. coli (CDEC), and Shiga toxin-producing E. coli (STEC) [12]. The latter pathotype includes a subgroup designated as enterohemorrhagic E. coli (EHEC), which is characterized by harboring the eae gene (encodes intimin, which is involved in attaching and effacing phenotype). The pathogenicity of STEC is mainly reliant on the development of one or two Shiga toxins (Stx1, Stx2), causing mild to severe symptoms of hemorrhagic colitis (HC). However, two major lethal syndromes, namely hemolytic uremic syndrome (HUS) and thrombotic thrombocytopenic purpura (TTP), have been reported as outcomes associated with STEC infection [13].

The evolution of resistance to clinically important antibiotics in foodborne bacteria, which can transmit antibiotic resistance determinants to human pathogens, is a critical public health concern. Notably, the propensity of E. coli to interchange genetic material with different bacteria makes them great candidates for understanding the reservoir of resistance genes in food of animal origin. One of the most prominent resistance mechanisms in E. coli that have been widely reported worldwide is the production of $\beta$-lactamases, particularly extended-spectrum $\beta$-lactamases (ESBL), which confer resistance to extended-spectrum cephalosporins such as cefotaxime, ceftriaxone, and ceftazidime [14]. Worryingly, ESBLproducing bacteria have shown co-resistance to several other classes of antimicrobials such as aminoglycosides, tetracyclines, quinolones, chloramphenicol, and sulfonamides. Consequently, third-generation cephalosporin-resistant $E$. coli was selected as an indicator to monitor antimicrobial resistance in food animals in the European Union [15]. However, there is a dearth of information about using such indicators for the surveillance of resistance to zoonotic antimicrobials in food of animal origin, particularly raw milk cheese. It is worth mentioning that harmonization of surveillance programs of antimicrobial resistance in humans, animals, and foods of animal origin all over the world, using known indicators, is important from a One Health perspective [16].

Of note, there are many studies on the phenotypic and molecular characteristics of coliforms and fecal coliforms in water and some dairy foods [6,17], but there are few reports on the phenotypic and molecular characteristics of this group in unpasteurized dairy products. Therefore, this study aimed to assess the hygienic status of raw milk cheese 
in Egypt, which could contribute to the development of public health protection monitoring and control activities for dairy industries.

\section{Materials and Methods}

\subsection{Collection of Samples}

A total of 200 karish cheese samples were collected from different small-scale supermarkets (60 samples), retail (100 samples), and dairy shops (40 samples) in the El-Menofia governorate of Egypt. All samples were produced not more than one day before the collection date and kept in the refrigerator for sale. Samples were collected in aseptic packages and transferred to our laboratory in an icebox. Upon arrival at the laboratory, they were maintained in the refrigerator at $4{ }^{\circ} \mathrm{C}$ and examined within $6 \mathrm{~h}$ of their arrival.

\subsection{Fecal Coliform Analysis}

Cheese samples $(25 \mathrm{~g}$ ) were diluted with $225 \mathrm{~mL}$ (dilution 1:10) of buffered peptone water (BPW) (Oxoid, Hampshire, UK) and homogenized in a stomacher. Seven consecutive dilutions (from $10^{-2}$ to $10^{-8}$ ) were performed. Coliform populations were estimated using the three-tube most-probable-number (MPN) method [18]. Briefly, one milliliter of the diluted cheese sample $\left(10^{-1}\right.$ to $\left.10^{-8}\right)$ was added to three lauryl sulfate tryptose broth tubes $(9 \mathrm{~mL})$ (Merck, Darmstadt, Germany) with inverted Durham tubes and incubated at $37^{\circ} \mathrm{C}$ for $48 \mathrm{~h} \mathrm{[18]}$. All gas-positive samples were then inoculated into Escherichia coli broth (EC broth) $\left(9 \mathrm{~mL}\right.$ ) (Oxoid, Hampshire, UK) and incubated at $44.5^{\circ} \mathrm{C}$ for $48 \mathrm{~h}$.

\subsection{Bacterial Identification}

The EC broth-positive samples were streaked onto eosin-methylene blue agar (EMB) (Oxoid, Hampshire, UK) and incubated at $35^{\circ} \mathrm{C}$ for $24 \mathrm{~h}$. Three colonies representing different morphological types on the EMB plates were subcultured for subsequent characterization. Isolated colonies were biochemically confirmed, as previously described [18].

\subsection{Antimicrobial Susceptibility Testing}

All isolates were characterized by antimicrobial susceptibility testing for 16 antimicrobials (Oxoid, Hampshire, UK) using a disc diffusion method in accordance with the Clinical and Laboratory Standards Institute (CLSI) guideline [19]. The selected antimicrobials are important in both clinical and agricultural settings and utilized to assess acquired resistance in E. coli and other Enterobacteriaceae [15,19]. They were as follows $(\mu \mathrm{g})$ : amoxicillin-clavulanic acid (20/10), ampicillin (10), aztreonam (30), cefepime (30), cefixime (5), cefotaxime (30), cefpirome (30), ceftazidime (30), ceftriaxone (30), ciprofloxacin (5), gentamicin (10), imipenem (10), nalidixic acid (30), streptomycin (10), sulfamethoxazoletrimethoprim (23/75), and tetracycline (30).

\subsection{Screening and Confirmatory Tests for $\beta$-Lactamase and Extended-Spectrum $\beta$-Lactamase (ESBL) Production}

All isolates were tested for $\beta$-lactamase production using nitrocefin (Oxoid, Hampshire, UK), as described previously [20]. Isolates showing $\beta$-lactamase production in the nitrocefin test were further screened for ESBL production by the double-disc synergy test (DDST). DDST was performed as a standard disc diffusion assay on Mueller Hinton agar (MHA) following CLSI recommendations [19]. All presumptive ESBL-producing isolates were subjected to phenotypic confirmation tests using ESBL clavulanic acid (CLA) combination discs [19]. Cefotaxime/clavulanic acid (CTX/CLA; 30/10 $\mu \mathrm{g}$ ) and ceftazidime/ clavulanic acid (CAZ/CLA; 30/10 $\mu \mathrm{g}$ ) discs (Becton Dickinson, East Rutherford, NJ, USA) were used. ESBL production was defined as an increase in the diameter of the zone of inhibition of $\geq 5 \mathrm{~mm}$ for either ceftazidime or cefotaxime in combination with clavulanic acid compared with the diameter when tested alone [19]. 


\subsection{Molecular Analysis}

Total DNA was extracted using a rapid boiling procedure, as previously described [21]. Enterobacterial repetitive intergenic consensus (ERIC)-PCR [22] and susceptibility patterns were used for clone delineation. One representative per clone was included. E. coli isolates were assigned to phylogenetic groups, as described previously [23]. The presence of virulence and antibiotic resistance genes was identified by PCR in isolated strains. Primer sequences are listed in Supplementary Table S1.

\subsection{Statistical Method}

Box-and-whisker plots using log10-transformed data of MPN/g were produced to visually explore the dispersions and central tendencies of the data [24]. The boxes illustrate median values (horizontal line through the box) and the interquartile range; the whisker lines represent the lowest and highest values within 1.5 times the interquartile range. Violon plots were also produced to represent the frequency of samples [24]. Both box-and-whisker and violin plots were prepared using R studio [25].

\subsection{Visualization of Genotypic and Phenotypic Patterns}

The ComplexHeatmap (v2.6.2) R package [26] was used to plot a summary heatmap for the resistance or susceptibility to different antimicrobials and the virulence patterns of our STEC strain and STEC strains identified in 17 studies published in the last decade.

\section{Results and Discussion}

Coliforms were detected in 94\% (188/200) of analyzed cheese samples. The majority of samples $(85 \%, 170 / 200)$ were unsuitable for consumption as they exceeded the maximum Egyptian standard for coliforms (10 MPN/g) [10]. The visual distribution of the MPN/g of coliforms and fecal coliforms is presented in Figure 1. The coliform counts ranged from a minimum of $3 \mathrm{MPN} / \mathrm{g}$ to a maximum of $9.3 \times 10^{5} \mathrm{MPN} / \mathrm{g}$ with a mean value of $1.5 \times 10^{5}$. Of note, $75 \%$ of samples contained more than $1.1 \times 10^{3} \mathrm{MPN} / \mathrm{g}$ (above the first quartile). However, a higher count of coliforms with a mean value of $2.9 \times 10^{7} \mathrm{cfu} / \mathrm{mL}$ was previously reported in Brazil [27]. On the other hand, in the US, a considerable percentage of raw milk cheeses $(42 \%)$ were contaminated with coliforms at a concentration of $>10 \mathrm{cfu} / \mathrm{g}$ [7]. Our data reveal how unsanitary manufacturing practices during the production and handling of raw milk cheese may jeopardize the product's microbiological quality, the situation that was reported in both developed and developing countries.

On the other hand, $65 \%(130 / 200)$ of samples exhibited fecal coliforms at $44.5^{\circ} \mathrm{C}$. The load of contamination by fecal coliforms was within the range of 16 to $3.4 \times 10^{5} \mathrm{MPN} / \mathrm{g}$, with $75 \%$ of samples containing more than $6.4 \times 10^{3} \mathrm{MPN} / \mathrm{g}$ (Figure 1 ). Notably, about half of the samples $(47.7 \%, 62 / 130)$ had fecal coliforms with concentrations between $10^{4}$ and $10^{5} \mathrm{MPN} / \mathrm{g}$. Similarly, Araujo et al. [28] reported a distinct distribution of fecal coliforms, with $93.3 \%$ of samples containing fecal coliforms from $10^{5}$ to $10^{6} \mathrm{MPN} / \mathrm{g}$. Interestingly, in developing countries, the dissemination of food safety awareness material has been minimal, and this study underlines the need for better hygiene measures for preparing raw milk cheese. Enhanced hygiene practices, including pasteurization on dairy farms and at small factories, should be carried out to improve the quality and safety of raw milk cheese.

Thermotolerant E. coli is the primary bacterium in fecal coliforms and is considered the most precise indication of fecal contamination because it does not come from the environment but is only seen in high quantities in the feces of humans and warm-blooded animals [5,7]. In this study, 150 strains were isolated at $44.5^{\circ} \mathrm{C}$. Analysis of the population structure of isolated strains revealed that most isolates were thermotolerant E. coli $(93.3 \%$, $140 / 150)$ and K. pneumoniae $(6.7 \%, 10 / 150)$. The high occurrence of thermotolerant E. coli in our samples revealed possible fecal contamination during milk collection and cheese processing. Regarding the limit of E. coli, unlike several international standards that set a permissible limit of 10-1000 E. coli in cheese samples [5], the Egyptian standard stated that karish cheese must be free from E. coli [10]. Given that E. coli was not detected in 
five cheese samples out of 130 samples containing fecal coliforms, thus $62.5 \%(125 / 200)$ of analyzed samples did not comply with the Egyptian standard. Higher occurrences of E. coli at percentages of $100 \%$ [27] and 97.7\% [28] were detected from cheese samples in Brazil. On the other hand, lower occurrences of 40\% [29] and 22\% [7] were reported in Mexico and the US, respectively. It is worth mentioning that while E. coli and fecal coliforms are thought to be linked to fecal contamination, they do not provide a sufficient level of resolution to distinguish between human and animal transmission routes.

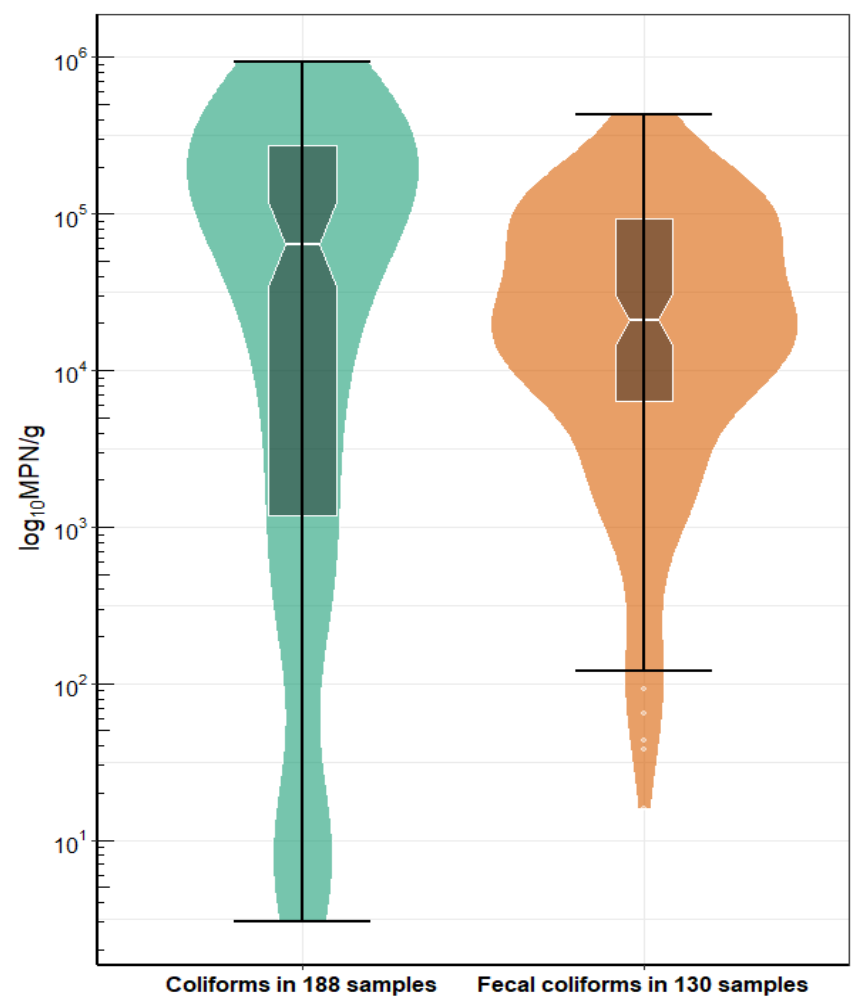

Figure 1. Violin plots overlaid on box and whisker plots showing the distribution of $\log 10 \mathrm{MPN} / \mathrm{g}$ of coliforms and fecal coliforms in raw milk cheese samples. The box represents $50 \%$ of data values, and the horizontal line within the box signifies the median. The upper and lower boundaries of the box are the 75th and 25th percentile, respectively. The whiskers (error bars) above and below the box represent the highest and lowest values within 1.5 times the interquartile range and indicate the 90th percentiles and 10th percentiles, respectively. White spots represent the outliers. The width of the violin plot reveals the frequency of samples.

Phylogenetic analyses have shown that E. coli strains belong to five phylogenetic groups (A, B1, B2, D, and F) [23]. Most commensal strains belong to groups A and B1, whereas virulent extra-intestinal strains belong mainly to group B2 and, to a lesser extent, group D [30]. Interestingly, detecting a specific phylogenetic group or groups in food isolates may prove valuable as a risk assessment marker for food safety research. In previous studies, animal and human E. coli isolates exhibited significant shifts in phylogenetic distribution, with the former being mainly from phylogenetic groups B1, while the latter was predominantly from phylogenetic group A [31-33]. In this study, phylogenetic analysis revealed that $88.6 \%(124 / 140)$ of $E$. coli isolates belonged to group $\mathrm{A}$, and some were from group B1, 11.4\% (16/140), suggesting that indirect fecal contamination probably originated from the cheese makers because of poor hygienic practices during the production of karish cheese.

Analysis of the susceptibility status of THC isolates revealed that $60(42.8 \%, 60 / 140)$ isolates were susceptible to all antibiotics tested, $47(33.6 \%, 47 / 140)$ isolates were resistant to one antibiotic, and $20(14.3 \%, 20 / 140)$ isolates were resistant to two antibiotics. Multiple 
resistance (to three or more antimicrobial agents) was observed in 13 isolates $(9.3 \%, 13 / 140)$. The phenotypic and genotypic characteristics of 80 thermotolerant $E$. coli strains that showed resistance to at least one antimicrobial are presented in Figure 2. Overall, the highest rates of resistance were observed for ampicillin $(30.7 \%, 43 / 140)$, cefixime $(16.4 \%$, $23 / 140)$, streptomycin $(16.4 \%, 23 / 140)$, and tetracycline $(12.8 \%, 18 / 140)$. Of note, none of the isolated strains were resistant to the fourth generation cephalosporins (cefepime and cefpirome), a carbapenem (imipenem), and monobactam (aztreonam). Visualization of the antimicrobial resistance profiles of isolated strains using a heatmap revealed three clusters (Figure 2). Cluster 1 and 2 included strains that were not resistant to any of the third-generation cephalosporins tested in this study. The majority of the strains $(83.7 \%$, $67 / 80$ ) showed resistance to one or two classes of antimicrobials and were included in cluster 1. Cluster 2 included two strains, KC-9 and KC-42, which showed resistance to antimicrobials belonging to three or more classes of antimicrobials and thus classified as multidrug-resistant strains. Cluster 3, on the other hand, was made up exclusively of isolates that were resistant to one or more third-generation cephalosporins as well as one or more antimicrobial classes.

Interestingly, in the recent ranking of medically essential antimicrobials conducted by the World Health Organization (WHO), third-generation cephalosporins were classified as "highest priority critically important antimicrobials" [34]. Thus, a closer follow-up for the emergence and dissemination of resistance to this group of antibiotics in animal and food of animal origin is essential for public health. A striking finding in this study is that 11 strains $(7.8 \%, 11 / 140)$, which made up cluster 3 , showed resistance to two or three clinically important third-generation cephalosporins, including cefotaxime $(6.4 \%, 9 / 140)$, ceftriaxone $(5.7 \%, 8 / 140)$ and ceftazidime $(7.1 \%, 10 / 140)$ (Figure 2$)$. Worryingly, nine $(6.4 \%, 9 / 140)$ strains were confirmed as ESBL-producers (KC-10, KC-18, KC-32, KC-40, KC-50, KC-53, KC-54, and KC-60), five $(3.6 \%, 5 / 140)$ strains (KC-40, KC-50, KC-53, KC-60, and KC-28) showed the antibiotic resistance pattern, "CRO (ceftriaxone) + CTX (cefotaxime) + CAZ (ceftazidime)", and three $(2.1 \%, 3 / 140)$ strains (KC40, KC-53, and KC54) considered as multidrug-resistant strains because they showed co-resistance to at least three different classes of antimicrobials.

Notably, the discovery of a ceftriaxone-resistant strain, KC-28, that was not an ESBL producer supports Tamma and Humphries' hypothesis [35] that non-susceptibility to thirdgeneration cephalosporins is not an accurate proxy for ESBL production. It was also not surprising that strains $\mathrm{KC}-5, \mathrm{KC}-10, \mathrm{KC}-18$, and $\mathrm{KC}-32$, which harbored either $b l a_{\mathrm{CTX}-\mathrm{M}}$ or $b l a_{\mathrm{SHV}}$, were susceptible to one or more third-generation cephalosporins, given that such genotype-phenotype discrepancy was previously described in clinical isolates [19]. Compared to our findings, a higher occurrence of ceftriaxone-resistant E. coli strains (17.3\%) was reported in Mexico [29]. However, our findings contrast with a previous study that could not detect cefotaxime resistance in 319 E. coli strains isolated from raw milk and raw milk cheese in Brazil [27]. Interestingly, the relatively high frequency of third-generation cephalosporine-resistant E. coli strains detected in this study prompts increased attention of researchers to routinely perform susceptibility to this group of antibiotics in food isolates. We believe that testing food isolates for resistance to at least three third-generation cephalosporins, such as ceftriaxone, cefotaxime, and ceftazidime is critical for accumulating sufficient antimicrobial resistance data in this type of cheese and determining the burden of its consumption.

Globally, antimicrobial resistance genes in commensal bacteria are an indirect risk to public health, as they increase the genomic pool from which pathogenic bacteria can acquire resistance genes. In this study, resistance to quinolones, which was included in the WHO list of highest priority critically important antimicrobials used for human treatment [34], was detected in one strain (KC-53) $(0.7 \%, 1 / 140)$ which carried the plasmidmediated quinolone resistance gene, qnrS (Figure 2). On the other hand, PCR amplification of $\beta$-lactam resistance genes showed that $4.3 \%(6 / 140)$ and $2.8 \%(4 / 140)$ of isolates were positive for $b l a_{\mathrm{SHV}}$, and $b l a_{\mathrm{CTX}-\mathrm{M}}$, respectively. Further, of the six tetracycline resistance genes screened, tet(A) and tet(B) were detected, with $2.1 \%(3 / 140)$ of strains carrying tet(A) 
and $0.71 \%(1 / 140)$ carrying tet(B). The antibiotic resistance genes detected in this study provided important clues about their ability to be horizontally transmitted, as they are usually carried on mobile genetic elements.

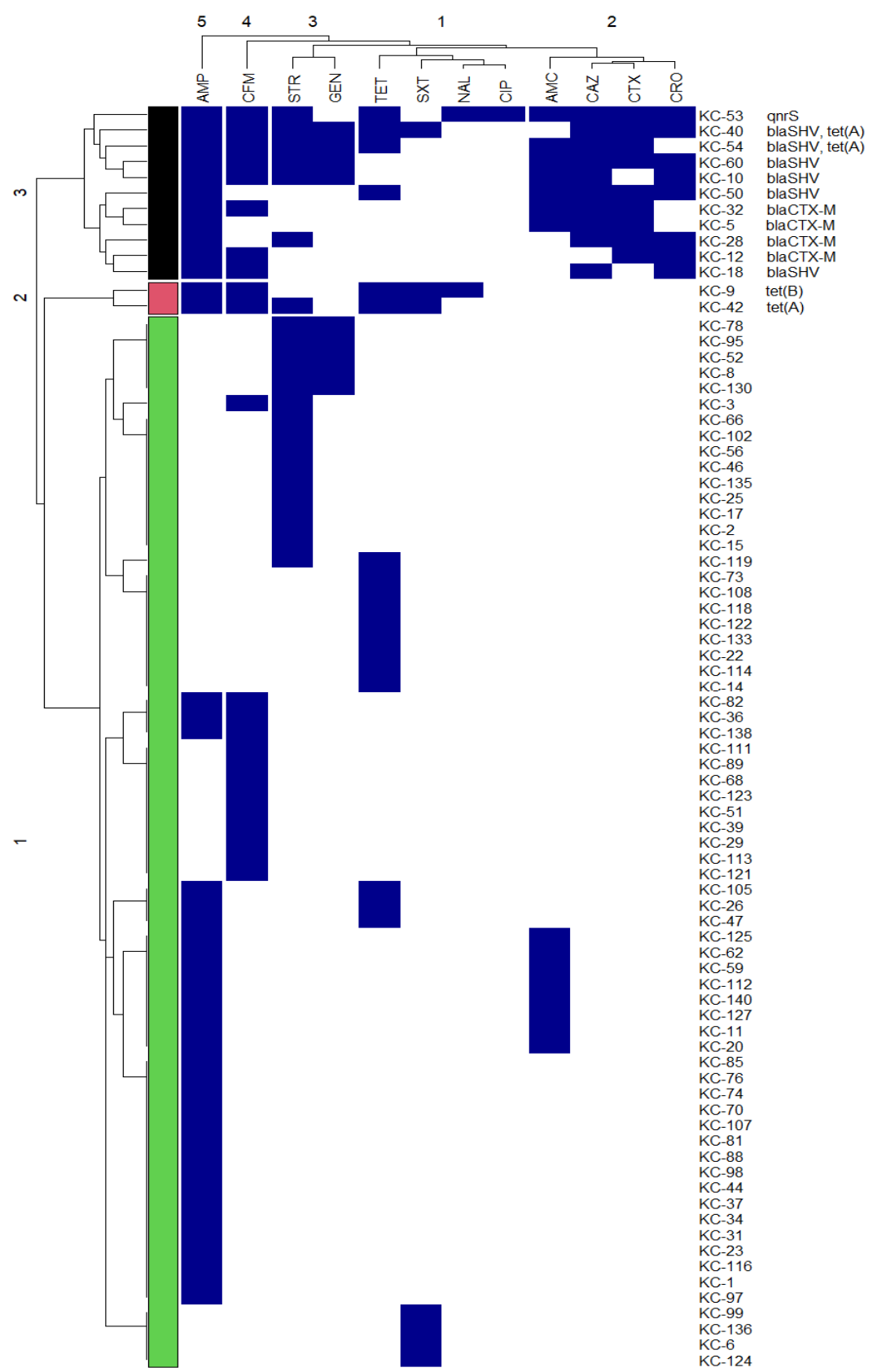

Figure 2. Heatmap showing antibiotic resistance profiles of thermotolerant E. coli strains. The numbers of strains are on the right of the heat map, followed by the identified antibiotic resistance genes. The dark blue color of the box indicates the resistance to the antimicrobial, while the white color indicates the susceptibility to the antimicrobial. The dendrogram on the left reflects the hierarchical clustering of antibiotic resistance profiles in the isolated strains. The numbers on the dendrogram ( 1 to 3 ) indicate the numbers of clusters. The dendrogram on the top reflects the hierarchical clustering of screened antibiotics. Abbreviations of the antimicrobials are AMC, amoxicillin-clavulanic acid; AMP, ampicillin; CAZ, ceftazidime; CFM, cefixime; CIP, ciprofloxacin; CRO, ceftriaxone; CTX, cefotaxime; GEN, gentamicin; NAL, nalidixic acid; STR, streptomycin; SXT, sulfamethoxazole-trimethoprim and TET, tetracycline. 
In Egypt, the over-counter availability of antibiotics and the lack of adequate antibiotic stewardship and laws to regulate the use of antibiotics for animals and people make it challenging to utilize antibiotics responsibly. As a result, finding multiple antibioticresistant and multidrug-resistant $E$. coli strains in retail raw milk cheese samples from Egypt is not surprising. However, in the absence of antimicrobial resistance pattern data for isolates from humans and animals in Egypt, it cannot be deduced with confidence whether contamination from animal, human, or both sources has occurred. Our findings corroborate that conducting national surveillance programs in Egypt for periodically monitoring the prevalence of antimicrobial-resistant E. coli strains in retail raw milk cheese is crucial to ensure its safety.

To gain insight into the role of karish as a vehicle for transmission of diarrheagenic E. coli, we examined different virulence factors in the isolated E. coli strains. One strain (KC-119) $(0.71,1 / 140)$ carried the sxt2 gene, which is alarming as epidemiological studies found that Stx2, not Stx1, is more frequently linked to severe illness and development of HUS $[36,37]$. Even though the absence of the intimin coding gene in this strain (eae) led to its exclusion of the enterohemorrhagic E. coli (EHEC) group but it still has the potential to be injurious to human health, considering that some eae-negative strains were found to be associated with human diseases [38]. Notably, the occurrence of STEC in raw milk cheeses showed a slightly wide variation between and within countries. For instance, on the one hand, the occurrence of STEC was 2.5\%, 2.25\%, $0 \%$, and $0 \%$ in raw milk cheese samples from Italy, Egypt, the US, and Brazil, respectively [39-41]. On the other hand, relatively higher occurrences of $5.7 \%$ and $8 \%$ were reported in Switzerland and Mexico, respectively $[29,42]$. Several hypotheses have been proposed to explain this issue, including loss of stx genes during isolation, the presence of high levels of competing bacteria, and natural inhibitors produced within dairy products that interfere with STEC isolation [43]. Given the risk of STEC transmission to humans through raw milk cheese-eating, as well as the serious health consequences of STEC infection, further study is urgently needed to address this problem and develop an agreement on the best procedure for isolating STEC from raw milk cheeses.

A striking finding of our study is the detection of virulence pattern, st $x 1-$, st $x 2+$, eae-, that was frequently detected in STEC strains isolated from cattle in different countries all over the world, such as Argentina [38,44], France [45], and Portugal [46]. To increase our understanding of the spread of this pattern in STEC isolated from raw milk cheeses, we investigated its occurrence among other patterns in STEC strains isolated from natural milk cheeses worldwide in the last decade. To this end, we constructed a heat map for depicting the virulence patterns of STEC reported in 17 studies. As illustrated in Figure 3, the virulence patterns were categorized into seven distinct clusters representing seven virulence patterns. Eleven studies $(61.11 \%, 11 / 18)$, including our study, found the virulence pattern "st $x 1-$, st $x 2+$, eae-," which makes up cluster 1 . STEC was shown to carry st $x 2$ with one or both stx 1 and eae genes in $13(72.2 \%, 13 / 18)$ investigations, forming clusters 4,5 , and 7. Our strain clustered with strains isolated from raw milk cheeses in Egypt and European countries, including France, England, Italy, and Switzerland. Surprisingly, this virulence pattern was detected in 27 out of 29 STEC strains isolated from raw milk cheese in Switzerland [42]. We assume that STEC strains carrying this virulence pattern may find their way to cheese through fecal contamination from cattle during the milking process. Worryingly, given that cheese-making processes can induce phage production, leading to the presence of Stx phages as free particles in cheeses [47], the possibility of other pathogenic and non-pathogenic bacteria acquiring st $x$ genes remains. Our findings, together with the data depicted in Figure 3 from the globally disseminated STEC, reveal that raw milk cheese is a potential reservoir of st $x$ genes, particularly st 2 , posing a threat to human health. 


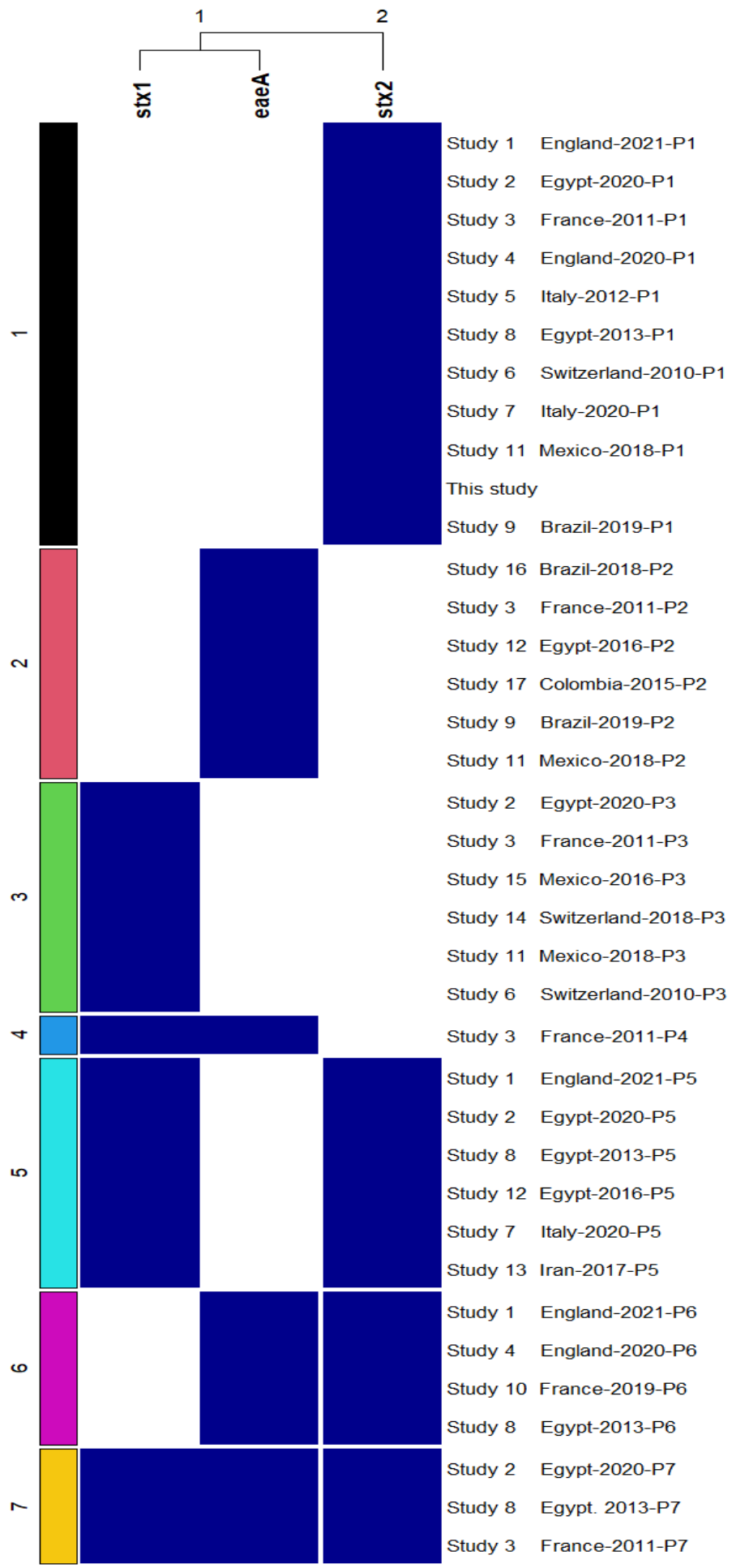

Figure 3. Heatmap showing virulence profiles of our strain and published strains isolated from raw milk cheeses in different countries in the last decade. All virulence patterns discovered in each of the 17 investigations were depicted once, regardless of their frequency. The dark blue color of the box indicates the presence of the gene, while the white color indicates the absence of the gene. On the right side of the heatmap, the country of origin of each strain and the year of publication of each study were written. The following studies were included: Study 1 [48]; Study 2 [49]; Study 3 [50]; Study 4 [51]; Study 5 [39]; Study 6 [42]; Study 7 [52]; Study 8 [53]; Study 9 [27]; Study 10 [54]; Study 11 [29]; Study 12 [40]; Study 13 [55]; Study 14 [56]; Study 15 [57]; Study 16 [41]; and Study 17 [58]. 


\section{Conclusions}

The high prevalence and loads of coliforms and fecal coliforms found in this study indicated that hygienic-sanitary failures occurred throughout the production process of most retail karish cheese in Egypt. In line with the earlier idea of employing indicators to track antimicrobial resistance in humans and food-producing animals [15], we propose that antimicrobial resistance surveillance systems in raw milk cheese be harmonized using markers like third-generation cephalosporin-resistant E. coli. These indicators are recommended to reflect the current state of antimicrobial resistance in this type of cheese and, as a result, to identify potential health hazards associated with its consumption. On the other hand, considering that contamination of raw milk cheese by STEC may not be entirely controlled through the cheesemaking process $[59,60]$, the finding of stx2-positive E. coli in this study, as well as other prior studies, highlights the importance of routine STEC surveillance in retail raw milk cheese to assure its safety.

Supplementary Materials: The following supporting information can be downloaded at: https: / / www.mdpi.com/article/10.3390/foods11030332/s1, Table S1: Primers used for PCR.

Author Contributions: Conceptualization, A.M.H.; methodology, A.M.H., N.H.A., H.H.; software, A.E. and H.A.H.; validation, H.A.H. and N.H.A.; formal analysis, H.A.H., A.E., and H.H; investigation, A.M.H., H.H., and A.E.; resources, N.H.A. and H.A.H.; data curation, A.E., H.H., and N.H.A.; writing—original draft preparation, A.M.H.; writing—review and editing, A.M.H. and T.S.; visualization, A.M.H., H.H., and A.E.; supervision, A.M.H. and T.S.; project administration, T.S.; funding acquisition, T.S. All authors have read and agreed to the published version of the manuscript.

Funding: This work was supported by a Grant-in-Aid for Scientific Research to T.S. from the Japan Society for the Promotion of Science (no. 25460532).

Data Availability Statement: The datasets used and analyzed during the current study are available from the corresponding author on reasonable request.

Conflicts of Interest: The authors declare no conflict of interest.

\section{References}

1. Zheng, X.; Shi, X.; Wang, B. A Review on the general cheese processing technology, flavor biochemical pathways and the influence of yeasts in cheese. Front. Microbiol. 2021, 12, 703284. [CrossRef] [PubMed]

2. Possas, A.; Bonilla-Luque, O.M.; Valero, A. From cheese-making to consumption: Exploring the microbial safety of cheeses through predictive microbiology models. Foods 2021, 10, 355. [CrossRef] [PubMed]

3. Van Asselt, E.D.; van der Fels-Klerx, H.J.; Marvin, H.J.P.; van Bokhorst-van de Veen, H.; Groot, M.N. Overview of food safety hazards in the European dairy supply chain. Compr. Rev. Food Sci. Food Saf. 2017, 16, 59-75. [CrossRef] [PubMed]

4. Mladenovic, K.G.; Grujovic, M.Z.; Kis, M.; Furmeg, S.; Tkalec, V.J.; Stefanovic, O.D.; Kocic-Tanackov, S.D. Enterobacteriaceae in food safety with an emphasis on raw milk and meat. Appl. Microbiol. Biotechnol. 2021, 105, 8615-8627. [CrossRef]

5. Metz, M.; Sheehan, J.; Feng, P.C.H. Use of indicator bacteria for monitoring sanitary quality of raw milk cheeses-A literature review. Food Microbiol. 2020, 85, 103283. [CrossRef]

6. Martin, N.H.; Trmcic, A.; Hsieh, T.H.; Boor, K.J.; Wiedmann, M. The evolving role of coliforms as indicators of unhygienic processing conditions in dairy foods. Front. Microbiol. 2016, 7, 1549. [CrossRef]

7. Trmcic, A.; Chauhan, K.; Kent, D.J.; Ralyea, R.D.; Martin, N.H.; Boor, K.J.; Wiedmann, M. Coliform detection in cheese is associated with specific cheese characteristics, but no association was found with pathogen detection. J. Dairy Sci. 2016, 99, 6105-6120. [CrossRef]

8. Doğan-Halkman, H.B.; Çakır, İ.; Keven, F.; Worobo, R.W.; Halkman, A.K. Relationship among fecal coliforms and Escherichia coli in various foods. Eur. Food Res. Technol. 2003, 216, 331-334. [CrossRef]

9. Doyle, M.P.; Erickson, M.C. The fecal coliform assay, the results of which have led to numerous misinterpretations over the years, may have outlived its usefulness. Microbe 2006, 4, 162-163.

10. 1008-4/2005; Soft Cheese. Part 4: Kareish Cheese; Egyptian Organization for Standardization and Quality Control: Cairo, Egypt, 2005.

11. Desvaux, M.; Dalmasso, G.; Beyrouthy, R.; Barnich, N.; Delmas, J.; Bonnet, R. Pathogenicity factors of genomic islands in intestinal and extraintestinal Escherichia coli. Front. Microbiol. 2020, 11, 2065. [CrossRef] [PubMed]

12. Pakbin, B.; Bruck, W.M.; Rossen, J.W.A. Virulence factors of enteric pathogenic Escherichia coli: A review. Int. J. Mol. Sci. 2021, 22, 9922. [CrossRef] [PubMed]

13. Travert, B.; Rafat, C.; Mariani, P.; Cointe, A.; Dossier, A.; Coppo, P.; Joseph, A. Shiga toxin-associated hemolytic uremic syndrome: Specificities of adult patients and implications for critical care management. Toxins 2021, 13, 306. [CrossRef] [PubMed] 
14. Castanheira, M.; Simner, P.J.; Bradford, P.A. Extended-spectrum beta-lactamases: An update on their characteristics, epidemiology and detection. JAC Antimicrob. Resist. 2021, 3, dlab092. [CrossRef] [PubMed]

15. ECDC; EFSA; EMA. ECDC, EFSA and EMA Joint Scientific Opinion on a list of outcome indicators as regards surveillance of antimicrobial resistance and antimicrobial consumption in humans and food-producing animals. EFSA J. 2017, 15 , e05017. [CrossRef]

16. McEwen, S.A.; Collignon, P.J. Antimicrobial resistance: A one health perspective. Microbiol. Spectr. 2018, 6. [CrossRef] [PubMed]

17. Genter, F.; Willetts, J.; Foster, T. Faecal contamination of groundwater self-supply in low- and middle income countries: Systematic review and meta-analysis. Water Res. 2021, 201, 117350. [CrossRef]

18. Downes, F.P.; Ito, K. Compendium of Methods for the Microbiological Examination of Foods; American Public Health Association: Washington, DC, USA, 2001.

19. CLSI. Performance Standards for Antimicrobial Susceptibility Testing, 30th ed.; Clinical and Laboratory Standards Institute: Wayne, PA, USA, 2020.

20. Livermore, D.M.; Brown, D.F. Detection of beta-lactamase-mediated resistance. J. Antimicrob. Chemother. 2001, 48 (Suppl. 1), 59-64. [CrossRef]

21. Féria, C.; Ferreira, E.; Correia, J.D.; Goncalves, J.; Canica, M. Patterns and mechanisms of resistance to beta-lactams and betalactamase inhibitors in uropathogenic Escherichia coli isolated from dogs in Portugal. J. Antimicrob. Chemother. 2002, 49, 77-85. [CrossRef]

22. Versalovic, J.; Koeuth, T.; Lupski, J.R. Distribution of repetitive DNA sequences in eubacteria and application to fingerprinting of bacterial genomes. Nucleic Acids Res. 1991, 19, 6823-6831. [CrossRef]

23. Clermont, O.; Christenson, J.K.; Denamur, E.; Gordon, D.M. The Clermont Escherichia coli phylo-typing method revisited: Improvement of specificity and detection of new phylo-groups. Environ. Microbiol. Rep. 2013, 5, 58-65. [CrossRef]

24. $\mathrm{Hu}, \mathrm{K}$. Become competent within one day in generating boxplots and violin plots for a novice without prior R experience. Methods Protoc. 2020, 3, 64. [CrossRef] [PubMed]

25. Team. R.C. R: A language and environment for statistical computing. R Foundation for Statistical Computing, Vienna, Austria Available online: https:/ / www.R-project.org/ (accessed on 30 December 2021).

26. Gu, Z.; Eils, R.; Schlesner, M. Complex heatmaps reveal patterns and correlations in multidimensional genomic data. Bioinformatics 2016, 32, 2847-2849. [CrossRef] [PubMed]

27. Ribeiro Junior, J.C.; Silva, F.F.; Lima, J.B.A.; Ossugui, E.H.; Teider Junior, P.I.; Campos, A.; Navarro, A.; Tamanini, R.; Ribeiro, J.; Alfieri, A.A.; et al. Molecular characterization and antimicrobial resistance of pathogenic Escherichia coli isolated from raw milk and Minas Frescal cheeses in Brazil. J. Dairy Sci. 2019, 102, 10850-10854. [CrossRef] [PubMed]

28. Araujo, V.S.; Pagliares, V.A.; Queiroz, M.L.; Freitas-Almeida, A.C. Occurrence of Staphylococcus and enteropathogens in soft cheese commercialized in the city of Rio de Janeiro, Brazil. J. Appl. Microbiol. 2002, 92, 1172-1177. [CrossRef]

29. De la Rosa-Hernandez, M.C.; Cadena-Ramirez, A.; Tellez-Jurado, A.; Gomez-Aldapa, C.A.; Rangel-Vargas, E.; Chavez-Urbiola, E.A.; Castro-Rosas, J. Presence of multidrug-resistant Shiga toxin-producing Escherichia coli, enteropathogenic Escherichia coli, and enterotoxigenic Escherichia coli on fresh cheeses from local retail markets in Mexico. J. Food Prot. 2018, 81, 1748-1754. [CrossRef]

30. Yu, D.; Banting, G.; Neumann, N.F. A review of the taxonomy, genetics, and biology of the genus Escherichia and the type species Escherichia coli. Can. J. Microbiol. 2021, 67, 553-571. [CrossRef]

31. Carlos, C.; Pires, M.M.; Stoppe, N.C.; Hachich, E.M.; Sato, M.I.; Gomes, T.A.; Amaral, L.A.; Ottoboni, L.M. Escherichia coli phylogenetic group determination and its application in the identification of the major animal source of fecal contamination BMC Microbiol. 2010, 10, 161. [CrossRef]

32. Ishii, S.; Meyer, K.P.; Sadowsky, M.J. Relationship between phylogenetic groups, genotypic clusters, and virulence gene profiles of Escherichia coli strains from diverse human and animal sources. Appl. Environ. Microbiol. 2007, 73, 5703-5710. [CrossRef]

33. Stoppe, N.C.; Silva, J.S.; Carlos, C.; Sato, M.I.Z.; Saraiva, A.M.; Ottoboni, L.M.M.; Torres, T.T. Worldwide phylogenetic group patterns of Escherichia coli from commensal human and wastewater treatment plant isolates. Front. Microbiol. 2017, $8,2512$. [CrossRef]

34. WHO. Critically Important Antimicrobials for Human Medicine-6th Revision 2018. Ranking of Antimicrobial Agents for Risk Management of Antimicrobial Resistance Due to Non-Human Use. Available online: http:/ /apps.who.int/iris/bitstream/10665/ 255027/1/9789241512220-eng.pdf (accessed on 30 December 2021).

35. Tamma, P.D.; Humphries, R.M. PRO: Testing for ESBL production is necessary for ceftriaxone-non-susceptible Enterobacterales: Perfect should not be the enemy of progress. JAC Antimicrob. Resist. 2021, 3, dlab019. [CrossRef] [PubMed]

36. Lee, K.S.; Jeong, Y.J.; Lee, M.S. Escherichia coli Shiga toxins and gut microbiota interactions. Toxins 2021, 13, 416. [CrossRef] [PubMed]

37. Abreu, A.G.; Barbosa, A.S. How Escherichia coli circumvent complement-mediated killing. Front. Immunol. 2017, 8, 452. [CrossRef] [PubMed]

38. Colello, R.; Kruger, A.; Velez, M.V.; Del Canto, F.; Etcheverria, A.I.; Vidal, R.; Padola, N.L. Identification and detection of iha subtypes in LEE-negative Shiga toxin-producing Escherichia coli (STEC) strains isolated from humans, cattle and food. Heliyon 2019, 5, e03015. [CrossRef] 
39. Volponi, G.; Rooks, D.J.; Smith, D.L.; Picozzi, C.; Allison, H.E.; Vigentini, I.; Foschino, R.; McCarthy, A.J. Characterization of Shiga toxin 2-carrying bacteriophages induced from Shiga-toxigenic Escherichia coli isolated from Italian dairy products. J. Dairy Sci. 2012, 95, 6949-6956. [CrossRef] [PubMed]

40. Ombarak, R.A.; Hinenoya, A.; Awasthi, S.P.; Iguchi, A.; Shima, A.; Elbagory, A.M.; Yamasaki, S. Prevalence and pathogenic potential of Escherichia coli isolates from raw milk and raw milk cheese in Egypt. Int. J. Food Microbiol. 2016, 221, 69-76. [CrossRef]

41. De Campos, A.; Puno-Sarmiento, J.J.; Medeiros, L.P.; Gazal, L.E.S.; Maluta, R.P.; Navarro, A.; Kobayashi, R.K.T.; Fagan, E.P.; Nakazato, G. Virulence genes and antimicrobial resistance in Escherichia coli from cheese made from unpasteurized milk in Brazil. Foodborne Pathog. Dis. 2018, 15, 94-100. [CrossRef]

42. Zweifel, C.; Giezendanner, N.; Corti, S.; Krause, G.; Beutin, L.; Danuser, J.; Stephan, R. Characteristics of Shiga toxin-producing Escherichia coli isolated from Swiss raw milk cheese within a 3-year monitoring program. J. Food Prot. 2010, 73, 88-91. [CrossRef]

43. Miszczycha, S.D.; Perrin, F.; Ganet, S.; Jamet, E.; Tenenhaus-Aziza, F.; Montel, M.C.; Thevenot-Sergentet, D. Behavior of different Shiga toxin-producing Escherichia coli serotypes in various experimentally contaminated raw-milk cheeses. Appl. Environ. Microbiol. 2013, 79, 150-158. [CrossRef]

44. Galli, L.; Miliwebsky, E.; Irino, K.; Leotta, G.; Rivas, M. Virulence profile comparison between LEE-negative Shiga toxin-producing Escherichia coli (STEC) strains isolated from cattle and humans. Vet. Microbiol. 2010, 143, 307-313. [CrossRef]

45. Pradel, N.; Livrelli, V.; De Champs, C.; Palcoux, J.B.; Reynaud, A.; Scheutz, F.; Sirot, J.; Joly, B.; Forestier, C. Prevalence and characterization of Shiga toxin-producing Escherichia coli isolated from cattle, food, and children during a one-year prospective study in France. J. Clin. Microbiol. 2000, 38, 1023-1031. [CrossRef]

46. Ballem, A.; Goncalves, S.; Garcia-Menino, I.; Flament-Simon, S.C.; Blanco, J.E.; Fernandes, C.; Saavedra, M.J.; Pinto, C.; Oliveira, H.; Blanco, J.; et al. Prevalence and serotypes of Shiga toxin-producing Escherichia coli (STEC) in dairy cattle from Northern Portugal. PLoS ONE 2020, 15, e0244713. [CrossRef] [PubMed]

47. Bonanno, L.; Delubac, B.; Michel, V.; Auvray, F. Influence of stress factors related to cheese-making process and to STEC detection procedure on the induction of Stx phages from STEC O26:H11. Front. Microbiol. 2017, 8, 296. [CrossRef] [PubMed]

48. Willis, C.; McLauchlin, J.; Aird, H.; Jorgensen, F.; Lai, S.; Sadler-Reeves, L. An assessment of the microbiological quality and safety of unpasteurised milk cheese for sale in England during 2019-2020. J. Food Prot. 2021. [CrossRef]

49. Elafify, M.; Khalifa, H.O.; Al-Ashmawy, M.; Elsherbini, M.; El Latif, A.A.; Okanda, T.; Matsumoto, T.; Koseki, S.; Abdelkhalek, A. Prevalence and antimicrobial resistance of Shiga toxin-producing Escherichia coli in milk and dairy products in Egypt. J. Environ. Sci. Health B 2020, 55, 265-272. [CrossRef]

50. Madic, J.; Vingadassalon, N.; de Garam, C.P.; Marault, M.; Scheutz, F.; Brugere, H.; Jamet, E.; Auvray, F. Detection of Shiga toxin-producing Escherichia coli serotypes O26:H11, O103:H2, O111:H8, O145:H28, and O157:H7 in raw-milk cheeses by using multiplex real-time PCR. Appl. Environ. Microbiol. 2011, 77, 2035-2041. [CrossRef]

51. McLauchlin, J.; Aird, H.; Elliott, A.; Forester, E.; Jorgensen, F.; Willis, C. Microbiological quality of raw drinking milk and unpasteurised dairy products: Results from England 2013-2019. Epidemiol. Infect. 2020, 148, e135. [CrossRef]

52. Cortimiglia, C.; Borney, M.F.; Bassi, D.; Cocconcelli, P.S. Genomic investigation of virulence potential in Shiga toxin Escherichia coli (STEC) strains from a semi-hard raw milk cheese. Front. Microbiol. 2020, 11, 629189. [CrossRef]

53. Elhadidy, M.; Mohammed, M.A. Shiga toxin-producing Escherichia coli from raw milk cheese in Egypt: Prevalence, molecular characterization and survival to stress conditions. Lett. Appl. Microbiol. 2013, 56, 120-127. [CrossRef]

54. Jones, G.; Lefevre, S.; Donguy, M.P.; Nisavanh, A.; Terpant, G.; Fougere, E.; Vaissiere, E.; Guinard, A.; Mailles, A.; de Valk, H.; et al Outbreak of Shiga toxin-producing Escherichia coli (STEC) O26 paediatric haemolytic uraemic syndrome (HUS) cases associated with the consumption of soft raw cow's milk cheeses, France, March to May 2019. Eurosurveillance 2019, 24. [CrossRef]

55. Chaleshtori, F.S.; Arani, N.M.; Aghadavod, E.; Naseri, A.; Chaleshtori, R.S. Molecular characterization of Escherichia coli recovered from traditional milk products in Kashan, Iran. Vet. World 2017, 10, 1264-1268. [CrossRef]

56. Serrano, N.S.; Zweifel, C.; Corti, S.; Stephan, R. Microbiological quality and presence of foodborne pathogens in raw milk cheeses and raw meat products marketed at farm level in Switzerland. Ital. J. Food Saf. 2018, 7, 7337. [CrossRef]

57. Guzman-Hernandez, R.; Contreras-Rodriguez, A.; Hernandez-Velez, R.; Perez-Martinez, I.; Lopez-Merino, A.; Zaidi, M.B.; Estrada-Garcia, T. Mexican unpasteurised fresh cheeses are contaminated with Salmonella spp., non-O157 Shiga toxin producing Escherichia coli and potential uropathogenic E. coli strains: A public health risk. Int. J. Food Microbiol. 2016, 237, 10-16. [CrossRef] [PubMed]

58. Amezquita-Montes, Z.; Tamborski, M.; Kopsombut, U.G.; Zhang, C.; Arzuza, O.S.; Gomez-Duarte, O.G. Genetic relatedness among Escherichia coli pathotypes isolated from food products for human consumption in Cartagena, Colombia. Foodborne Pathog. Dis. 2015, 12, 454-461. [CrossRef] [PubMed]

59. Rios, E.A.; Ramos-Pereira, J.; Santos, J.A.; Lopez-Diaz, T.M.; Otero, A.; Rodriguez-Calleja, J.M. Behaviour of non-O157 STEC and atypical EPEC during the manufacturing and ripening of raw milk cheese. Foods 2020, 9, 1215. [CrossRef] [PubMed]

60. Peng, S.; Tasara, T.; Hummerjohann, J.; Stephan, R. An overview of molecular stress response mechanisms in Escherichia coli contributing to survival of Shiga toxin-producing Escherichia coli during raw milk cheese production. J. Food Prot. 2011, 74, 849-864. [CrossRef] 